\title{
Pt, Ir, Ru, and Rh Nanoparticles Supported on ZIF-67 Nanocubes for Evaluation of Hydrogen Spillover Ability of Noble Metals
}

\author{
Yu Shao and Hua Chun Zeng* \\ Integrative Sciences and Engineering Programme, NUS Graduate School and Department of \\ Chemical and Biomolecular Engineering, Faculty of Engineering, National University of Singa- \\ pore, 10 Kent Ridge Crescent, Singapore 119260 \\ *Email: chezhc@nus.edu.sg
}

Table of Contents

Table S1

Table S2

Table S3

Table S4

Figure S1

Figure S2

Figure S3

Figure S4

Figure S5

Figure S6

Figure S7

Figure S8

Figure S9

Figure S10
Page S-2

Page S-3

Page S-3

Page S-4

Page S-5

Page S-6

Page S-7

Page S-9

Page S-10

Page S-11

Page S-12

Page S-14

Page S-15

Page S-17
Figure S11

Figure S12

References
Page S-19

Page S-18

Page S-19 
Table S1. Summary of hydrogen spillover applications with multiple precious metals.

\begin{tabular}{|c|c|c|c|c|c|c|c|}
\hline Support & $\begin{array}{l}\text { Preparation } \\
\text { Method }\end{array}$ & $\begin{array}{l}\text { Metal } \\
\text { loading }\end{array}$ & $\begin{array}{l}\text { Metal NP } \\
\text { size }\end{array}$ & $\begin{array}{l}\text { Comparison } \\
\text { Method }\end{array}$ & $\begin{array}{l}\text { Comparison } \\
\text { Basis }\end{array}$ & $\begin{array}{l}\text { Compari- } \\
\text { son Result }\end{array}$ & Ref. \\
\hline $\mathrm{Fe}_{2} \mathrm{O}_{3}$ & $\begin{array}{l}\text { Incipient wet } \\
\text { impregnation }\end{array}$ & $\begin{array}{l}5.1 \times 10^{-5} \\
\mathrm{~mol} \cdot \mathrm{g}^{-1}\end{array}$ & $\mathrm{~N} / \mathrm{A}$ & TPR & $\begin{array}{l}\text { Reduction } \\
\text { temperature } \\
\text { (low }>\text { high) }\end{array}$ & $\mathrm{Rh}>\mathrm{Pt}>\mathrm{Pd}$ & 1 \\
\hline $\mathrm{Co}_{3} \mathrm{O}_{4}$ & $\begin{array}{l}\text { Incipient wet } \\
\text { impregnation }\end{array}$ & $1 \mathrm{wt} \%$ & $\mathrm{~N} / \mathrm{A}$ & TPR & $\begin{array}{l}\text { Reduction } \\
\text { temperature } \\
\text { (low > high) }\end{array}$ & $\begin{array}{l}\mathrm{Pt}>\mathrm{Ru}>\mathrm{Pd} \\
>\mathrm{Rh}\end{array}$ & 2 \\
\hline $\mathrm{Co} / \mathrm{Al}_{2} \mathrm{O}_{3}$ & $\begin{array}{l}\text { Incipient wet } \\
\text { impregnation }\end{array}$ & $0.5 \mathrm{wt} \%$ & $\mathrm{~N} / \mathrm{A}$ & TPR & $\begin{array}{l}\text { Reduction } \\
\text { temperature } \\
\text { (low }>\text { high) }\end{array}$ & $\mathrm{Ru}>\mathrm{Pd}>\mathrm{Pt}$ & 3 \\
\hline $\mathrm{Al}_{2} \mathrm{O}_{3}$ & $\begin{array}{l}\text { Commercial } \\
\text { catalyst }\end{array}$ & $0.5 \mathrm{wt} \%$ & $\mathrm{~N} / \mathrm{A}$ & $\begin{array}{l}\mathrm{WO}_{3} \text { color } \\
\text { change/ } \\
\text { Benzene } \\
\text { Hydrogenation }\end{array}$ & $\begin{array}{l}\mathrm{WO}_{3} \text { color } \\
\text { change/ } \\
\text { Adsorption } \\
\text { equilibrium } \\
\text { constant for } \mathrm{H}_{2} \\
\text { of catalyst }\end{array}$ & $\begin{array}{l}\mathrm{Pd}>\mathrm{Pt}>\mathrm{Rh} \\
>\mathrm{Ru}\end{array}$ & 4 \\
\hline $\mathrm{Al}_{2} \mathrm{O}_{3}$ & $\begin{array}{l}\text { Commercial } \\
\text { catalyst }\end{array}$ & $\begin{array}{l}\text { Ru: } 0.48 w t \% \\
\text { Rh: } 0.47 w t \% \\
\text { Pd: } 0.48 w t \% \\
\text { Pt: } 0.50 w t \%\end{array}$ & $\mathrm{~N} / \mathrm{A}$ & $\begin{array}{l}\text { Hydrodesulph- } \\
\text { urization (HDS) }\end{array}$ & $\begin{array}{l}\text { Catalytic } \\
\text { activity in HDS }\end{array}$ & $\begin{array}{l}\mathrm{Pt}>\mathrm{Pd}>\mathrm{Rh} \\
>\mathrm{Ru}\end{array}$ & 5 \\
\hline $\mathrm{ZnO}$ & $\begin{array}{l}\mathrm{Cu} / \mathrm{ZnO} \text { : } \\
\text { decomposition } \\
\text { and reduction of } \\
\text { carbonate } \\
\text { Pt/ZnO: } \\
\text { photodeposition } \\
\text { Ru/ZnO: } \\
\text { impregnation } \\
\text { and solvent } \\
\text { removal }\end{array}$ & $\begin{array}{l}\mathrm{Cu} / \mathrm{ZnO}: \mathrm{N} / \mathrm{A} \\
\mathrm{Pt} / \mathrm{ZnO}: \\
1 \mathrm{~mol} \% \\
\mathrm{Ru} / \mathrm{ZnO}: \\
0.5 \mathrm{~mol} \%\end{array}$ & $\begin{array}{l}\mathrm{Cu}: 4 \mathrm{~nm} \\
\mathrm{Pt}: 4 \mathrm{~nm} \\
\mathrm{Ru}: \\
<1 \mathrm{~nm}\end{array}$ & $\begin{array}{l}\text { IR } \\
\text { Transparency }\end{array}$ & $\begin{array}{l}\text { Increment in IR } \\
\text { transparency }\end{array}$ & $\mathrm{Ru}>\mathrm{Pt}$ & 6 \\
\hline Carbon & $\begin{array}{l}\text { Commercial } \\
\text { catalyst }\end{array}$ & $40 \%$ & $\begin{array}{l}\text { Pt: } 4 \mathrm{~nm} \\
\mathrm{Ru}: \\
3.4 \mathrm{~nm}\end{array}$ & $\begin{array}{l}\text { Inelastic } \\
\text { Neutron } \\
\text { Scattering }\end{array}$ & $\begin{array}{l}\text { Hydrogen } \\
\text { uptake ratio }\end{array}$ & $\mathrm{Ru}>\mathrm{Pt}$ & 7 \\
\hline Carbon & $\begin{array}{l}\text { Commercial } \\
\text { catalyst }\end{array}$ & $\begin{array}{l}\mathrm{Pd}, \mathrm{Pt}, \mathrm{Rh}, \mathrm{Ru}: \\
5 \mathrm{wt} \% \\
\text { Ir: } 1 \mathrm{wt} \%\end{array}$ & $\begin{array}{l}\text { Pd: } \\
3.7 \mathrm{~nm} \\
\text { Rh: } \\
3.5 \mathrm{~nm} \\
\text { Ru: } \\
11.8 \mathrm{~nm} \\
\text { Pt: } 4.7 \mathrm{~nm} \\
\text { Ir: } 3.7 \mathrm{~nm}\end{array}$ & $\begin{array}{l}\mathrm{BrO}_{3}^{-} \\
\text {reduction }\end{array}$ & $\begin{array}{l}\text { Catalytic } \\
\text { reduction } \\
\text { activity }\end{array}$ & $\begin{array}{l}\mathrm{Rh}>\mathrm{Ir}>\mathrm{Pt} \\
\sim \mathrm{Pd} \sim \mathrm{Ru}\end{array}$ & 8 \\
\hline
\end{tabular}

Note: These previous works on hydrogen spillover applications vary a lot in terms of their material preparation, nanoparticle morphology and comparison methods. Most of them did not explicitly compare the hydrogen spillover ability of different metals. This table is summarized based on information extracted from these works. 
Table S2. Summary of characteristic XRD peak information.

\begin{tabular}{|c|c|c|c|c|}
\hline $\begin{array}{l}\text { Element/Com- } \\
\text { pound }\end{array}$ & Major peak & 2 Theta & $d$ spacing & JCPDS card No. \\
\hline$\overline{\mathrm{Pt}}$ & $\left(\begin{array}{lll}1 & 1 & 1\end{array}\right)$ & 39.763 & 2.265 & 04-0802 \\
\hline PtO & $\left(\begin{array}{lll}1 & 0 & 1\end{array}\right)$ & 33.581 & 2.666 & $43-1100$ \\
\hline $\mathrm{Ru}$ & $\left(\begin{array}{lll}1 & 0 & 1\end{array}\right)$ & 44.005 & 2.056 & $06-0663$ \\
\hline $\mathrm{RuO}_{2}$ & $\left(\begin{array}{lll}1 & 1 & 0\end{array}\right)$ & 28.009 & 3.183 & $40-1290$ \\
\hline $\mathrm{Rh}$ & $\left(\begin{array}{lll}1 & 1 & 1\end{array}\right)$ & 41.068 & 2.196 & $05-0685$ \\
\hline $\mathrm{RhO}_{2}$ & $\left(\begin{array}{lll}1 & 1 & 0\end{array}\right)$ & 28.090 & 3.174 & $43-1026$ \\
\hline $\mathrm{Rh}_{2} \mathrm{O}_{3}$ & $\left(\begin{array}{lll}1 & 1 & 0\end{array}\right)$ & 34.924 & 2.567 & $25-0707$ \\
\hline Ir & $\left(\begin{array}{lll}1 & 1 & 1\end{array}\right)$ & 40.662 & 2.217 & 06-0598 \\
\hline $\mathrm{IrO}_{2}$ & $\left(\begin{array}{lll}1 & 1 & 0\end{array}\right)$ & 28.054 & 3.178 & $15-0870$ \\
\hline $\mathrm{Au}$ & $\left(\begin{array}{lll}1 & 1 & 1\end{array}\right)$ & 38.184 & 2.355 & $04-0784$ \\
\hline $\mathrm{Pd}$ & $\left(\begin{array}{lll}1 & 1 & 1\end{array}\right)$ & 40.118 & 2.246 & $46-1403$ \\
\hline $\mathrm{Ag}$ & $\left(\begin{array}{lll}1 & 1 & 1\end{array}\right)$ & 38.116 & 2.359 & 04-0783 \\
\hline
\end{tabular}

Table S3. Summary of ICP-OES results and calculation for ZIF-67/M.

\begin{tabular}{lllll}
\hline Sample Name & Element & Atomic Weight & wt \% metal & mmol metal/g ZIF-67 \\
\hline ZIF-67 NCs & - & - & 0 & 0 \\
ZIF-67/Pt & $\mathrm{Pt}$ & 195.08 & 4.38 & 0.23 \\
ZIF-67/Ru & $\mathrm{Ru}$ & 101.07 & 2.09 & 0.21 \\
ZIF-67/Rh & $\mathrm{Rh}$ & 102.91 & 2.25 & 0.22 \\
ZIF-67/Ir & $\mathrm{Ir}$ & 192.22 & 4.11 & 0.22 \\
\hline
\end{tabular}

Note: The molar loadings are calculated based on ICP-OES measured weight fractions and atomic weights of the metals. Due to the different affinities of MPA with the metal NPs, the amounts of Solution $A$ and metal NP solution used are not identical for each sample. 
Table S4. Summary of quantitative interpretation of XPS results

\begin{tabular}{llllll}
\hline Sample Name & $\begin{array}{l}\text { Co 2p Area } \\
\text { (cps·eV) }\end{array}$ & Co 2p RSF & $\begin{array}{l}\text { Metal Area } \\
\text { (cps·eV) }\end{array}$ & Metal RSF & $\begin{array}{l}\text { Co/Metal } \\
\text { Atomic Ratio }\end{array}$ \\
\hline ZIF-67/Pt & 9481.5 & 3.590 & 6795.5 & 5.575 & $1.94: 1$ \\
ZIF-67/Ru & 27810.9 & 3.590 & 8818.9 & 2.043 & $1.71: 1$ \\
ZIF-67/Rh & 27350.9 & 3.590 & 14767.0 & 4.822 & $2.28: 1$ \\
ZIF-67/Ir & 33306.4 & 3.590 & 23922.9 & 5.021 & $1.75: 1$ \\
\hline
\end{tabular}

Notes:

RSF - Relative Sensitivity Factor

The quantitative report was generated with the "VISION processing" program calibrated for the XPS instrument used.

Theoretically, for $0.22 \mathrm{mmol}$ metal/ $1 \mathrm{~g}$ ZIF-67 (4.52 mmol ZIF-67) loading, the Co to metal atomic ratio should be about $20.6: 1$. The much lower Co to metal atomic ratio indicates the concentrated distribution of the metal species at the exterior surface region, since the XPS instrument used was only capable of probing $\sim 10 \mathrm{~nm}$ depth into the material. These results may not be quantitatively accurate enough, but they should be able to serve as an supplementary evidence of the exclusive deposition of metal NPs on the external surfaces of ZIF-67 NCs. 


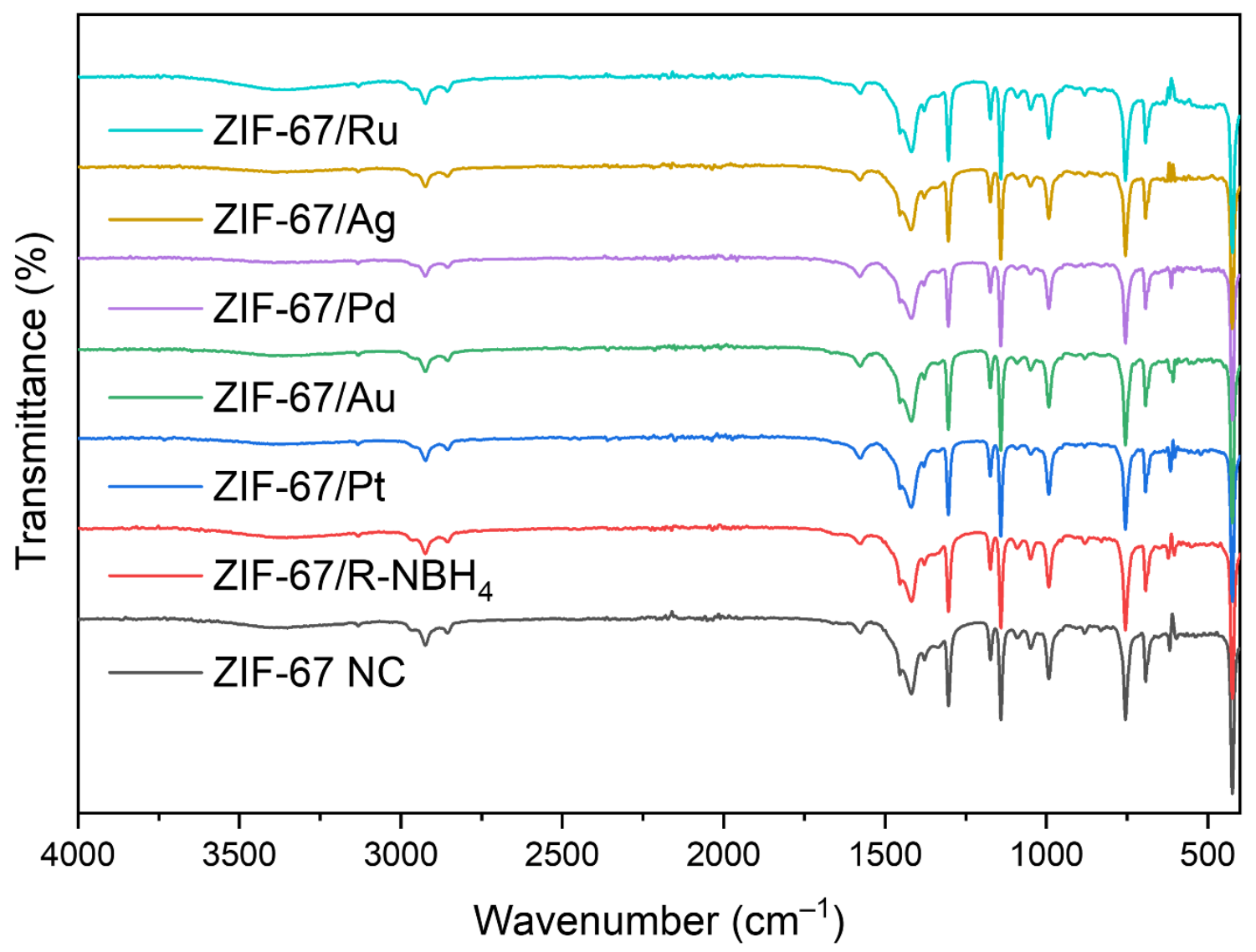

Figure S1. FTIR spectra for ZIF-67 NCs, ZIF-67 treated with R-NBH4 (ZIF-67/R-NBH4) and ZIF-67/M samples prepared via the in situ reduction method.

Note: Hardly, any obvious changes could be observed before and after the in situ reduction procedure to load the metal NPs. It is thus inferred that minimal influence on the chemical bonding condition was imposed by the reducing agent during this process. 


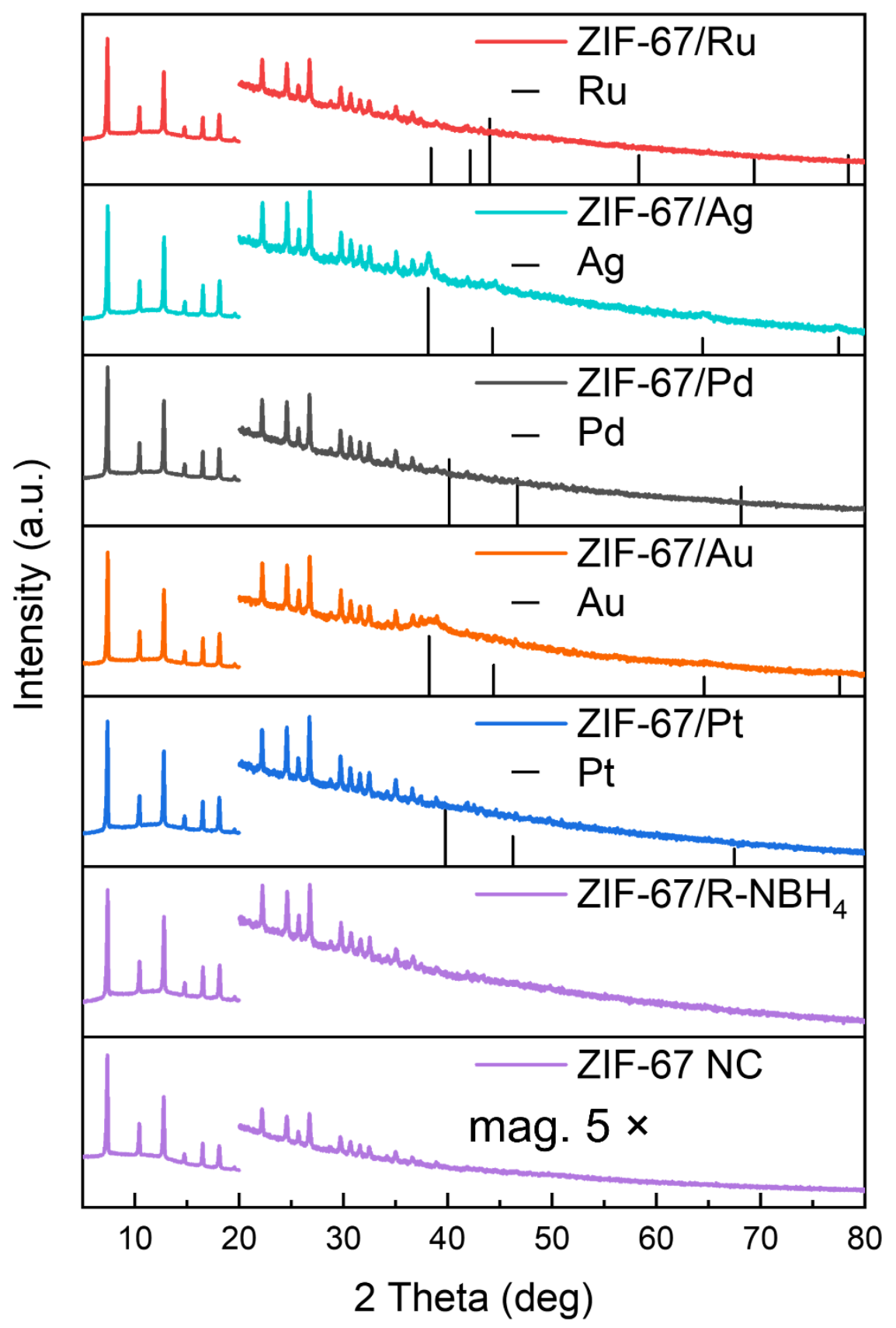

Figure S2. XRD patterns for ZIF-67 NCs and their derivatives prepared via in situ reduction method. Diffraction data above 2 Theta $=20^{\circ}$ are shown in $5 \times$ magnification, and some curves have been vertically shifted for better clarification.

Note: While the most prominent peak positions for the metal NPs in their typical forms are marked out, the in situ reduction generated sample in general display characteristic ZIF-67 XRD spectra due to the small size of the metal NPs with the exception of Ag NPs. 


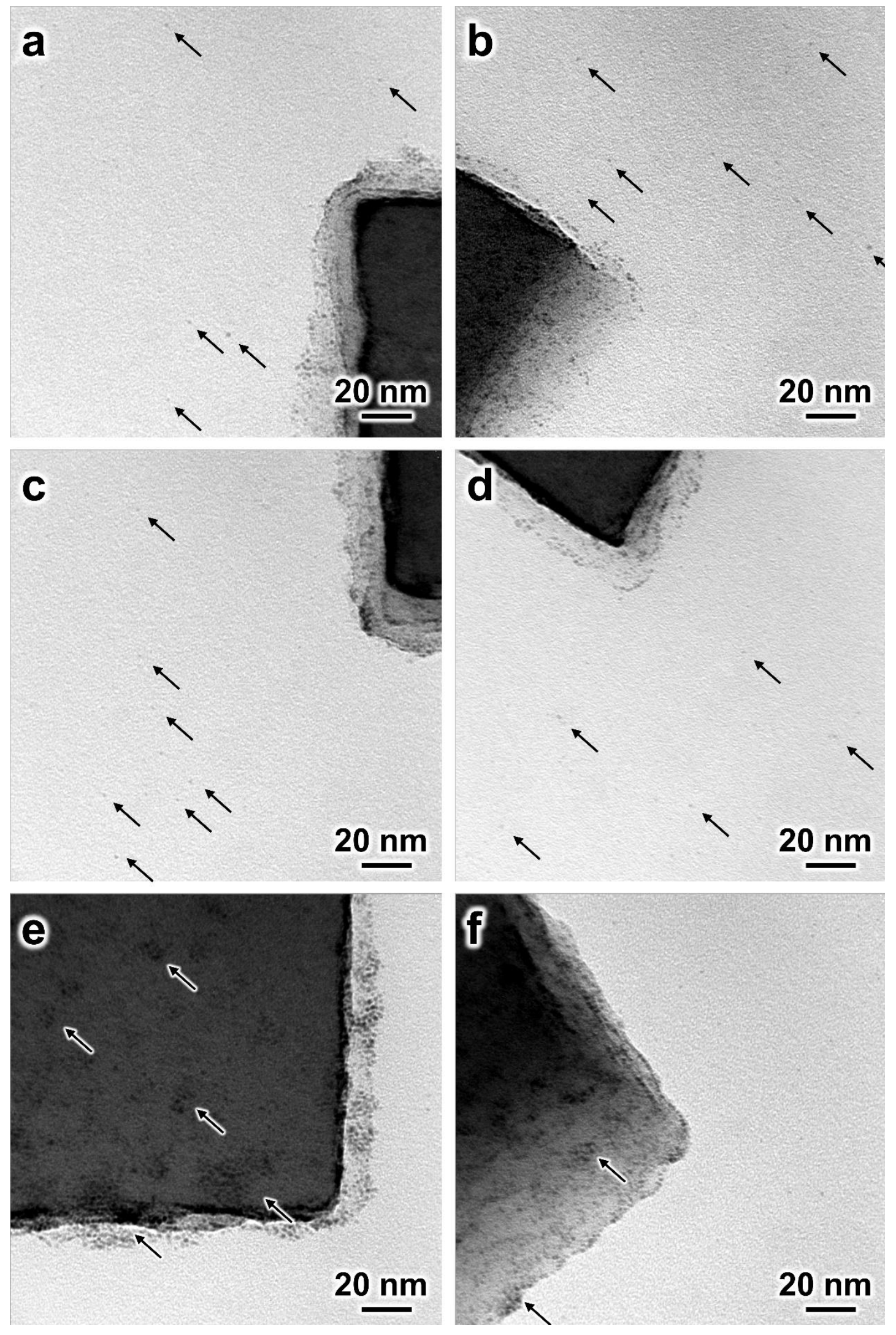

Figure S3. (a-f) TEM images of ZIF-67/Pt prepared via the direct impregnation method. 
Note: The black arrows in (a-d) highlight the Pt NPs positioned on the TEM sample grid coating, distant from the ZIF-67/Pt particles. Since the TEM samples were prepared by re-dispersing the dried ZIF-67/Pt sample into an ethanolic suspension, transferring them onto a TEM sample grid and subsequent drying, the observed Pt NPs should only originate from the same "ZIF-67/Pt" sample that is to be analyzed by TGA. The "deposited" Pt NPs were easily detached via a few seconds of ultra-sonication and precipitated onto the TEM sample grid upon drying. It is hence concluded that there is a lack of strong chemical interaction between the metal NPs and ZIF-67 surfaces, or lacking sufficient interfacial binding between them, as mentioned in the discussion for Figure 4 in the main text.

The observed "deposition" of Pt NPs is hence likely a result of Pt NPs precipitating on the ZIF-67 NCs upon solvent removal. Such a deposition process is uncontrolled as illustrated in Figure S3e-f. The black arrows in (e-f) highlight the regions with relatively high Pt NPs concentration. It is, however, desirable to have an even metal NP distribution to facilitate reliable comparison.

It is noteworthy that, the detachment of Pt NPs during TEM sample preparation and TGA analysis, as well as the uneven distribution of metal NPs are not observed in the samples prepared via the MPA-bridging method, as evidenced in Figure 5 and Figure S11. 

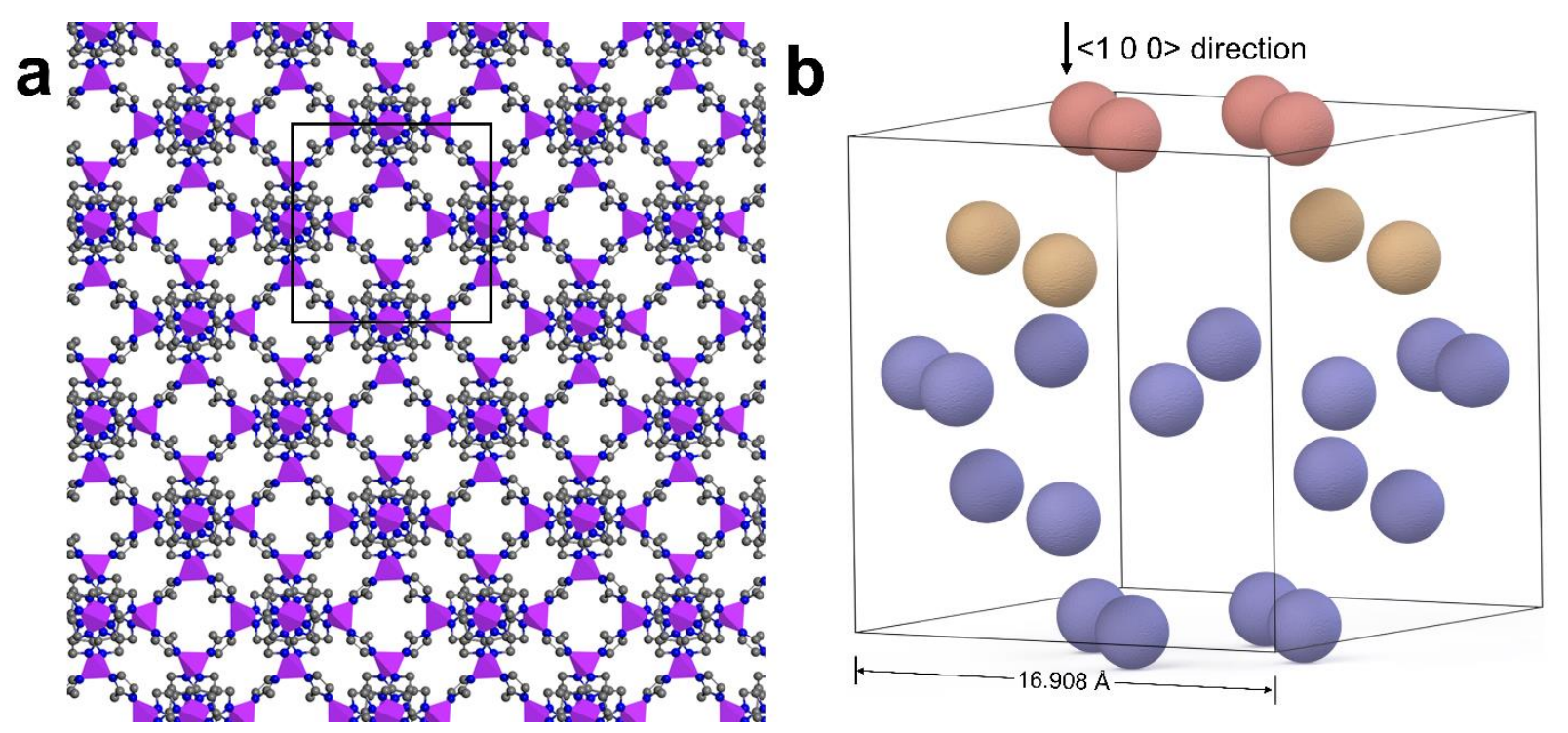

Figure S4. (a) ZIF-67 matrix seen along $<100>$ direction, with a unit cell highlighted. Color code: magenta represents cobalt, grey represents carbon, blue represents nitrogen and white represents hydrogen. (b) enlarged view of a unit cell, with only $\mathrm{Co}^{2+}$ nodes displayed for better visibility. Spheres in different colors all represent cobalt ions.

Note: Typical ZIF-67 materials have a unit cell dimension of $a_{0}=16.908 \AA$, a surface $\mathrm{Co}^{2+}$ ion density of $4 / a_{0}{ }^{2}$ on the $(100)$ facets and a density of $\rho=0.9 \mathrm{~g} / \mathrm{cm}^{3}{ }^{3 .-12}$ As illustrated in Figure S4b, when viewing the surfaces of ZIF-NCs from the $<100>$ direction, 4 cobalt ions (highlighted in red) are most exposed while another 4 sub-surface cobalt ions (highlighted in yellow) are adjacent to the surface. The other cobalt ions highlighted in blue are considered less exposed. Since the 4 cobalt ions highlighted in yellow are shared by adjacent unit cells, we hence consider 6 cobalt ions per unit cell for coordination by MPA molecules.

As the prepared ZIF-67 NCs has a dimension of $150 \mathrm{~nm}$, it is hence estimated that $7.85 \times$

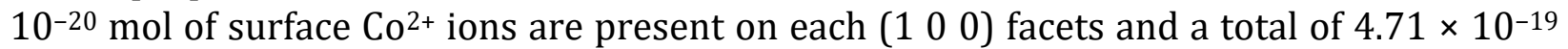
mol of surface $\mathrm{Co}^{2+}$ ions for each single nanocube. Meanwhile, $120 \mathrm{mg}$ of the prepared ZIF$67 \mathrm{NCs}$ is estimated to have $3.96 \times 10^{13}$ nanocubes. To coordinate each cobalt ions with 2 MPA molecules, $3.72 \times 10^{-5} \mathrm{~mol}$ of MPA is required. Since MPA has molecular weight of $106.14 \mathrm{~g} / \mathrm{mol}$ and density of $\rho=1.218 \mathrm{~g} / \mathrm{cm}^{3}$, the above specified amount would correspond to $3.24 \mu \mathrm{L}$ MPA (per $120 \mathrm{mg}$ ZIF-67 NCs).

$$
\frac{\left(\frac{150 \times 10^{-9}}{16.908 \times 10^{-10}}\right)^{2} \times 6}{6.02 \times 10^{23}} \times 6 \times \frac{\frac{120 \times 10^{-3}}{0.9} \times 10^{-6}}{\left(150 \times 10^{-9}\right)^{3}} \times 2 \times \frac{106.14}{1.218} \times 10^{3}=3.24(\mu L)
$$

The amount would correspond to $\mathbf{0 . 6 5} \mathbf{~ m L}$ of Solution A per $120 \mathrm{mg}$ ZIF-67 NCs. 


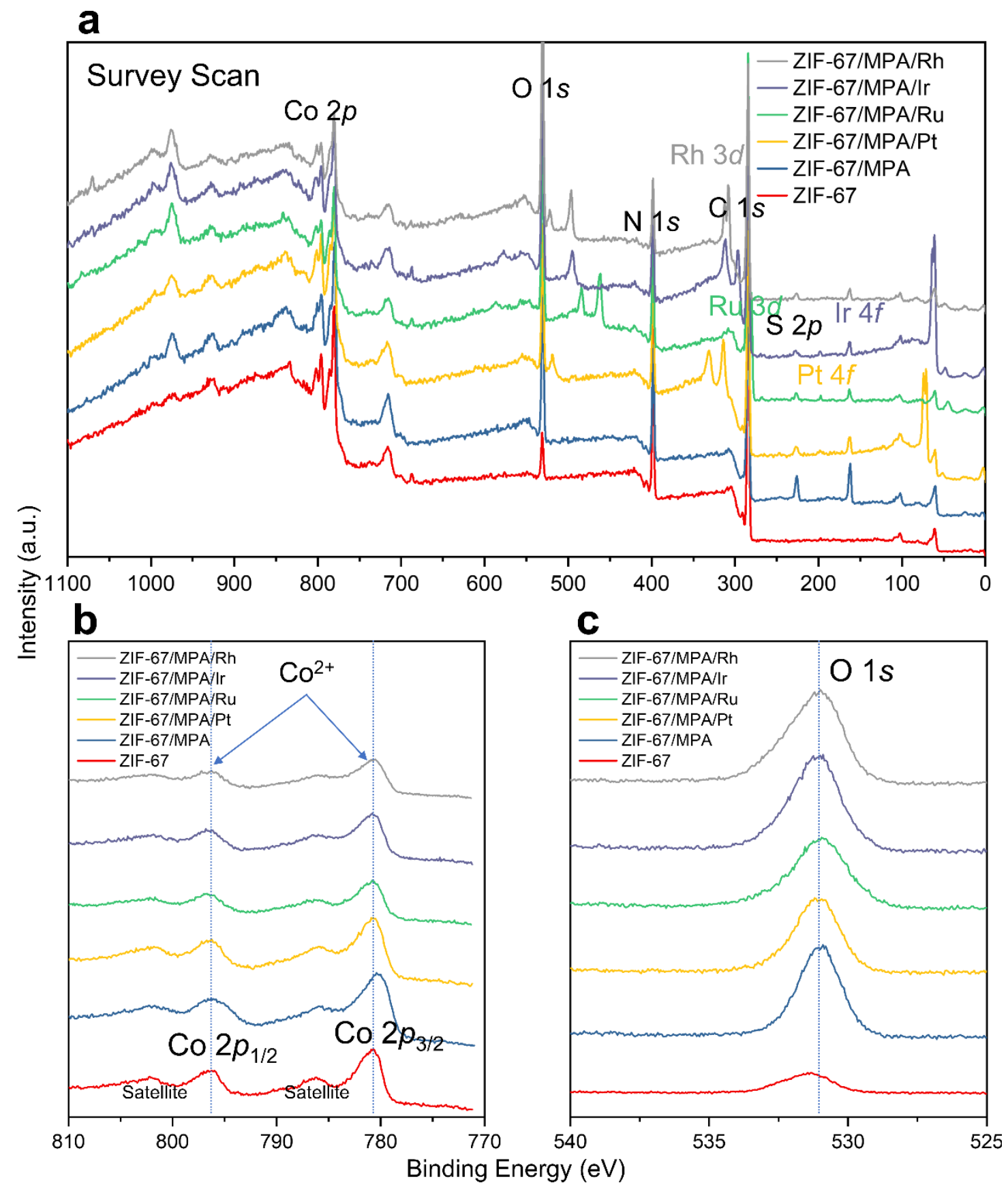

Figure S5. XPS results for ZIF-67 NCs and their derivatives, including ZIF-67/MPA, ZIF67/MPA/Pt, ZIF-67/MPA/Ru, ZIF-67/MPA/Ir, and ZIF-67/MPA/Rh: (a) Survey scan, (b) Co $2 p$ region, and (c) $01 s$ region (ZIF-67/M are denoted as ZIF-67/MPA/M to highlight the presence of MPA).

Note: The successful incorporation of metal NPs can be testified by the emergence of their characteristic binding energy peaks in the survey scan. The binding energies for cobalt and oxygen are hardly altered during the deposition process. 

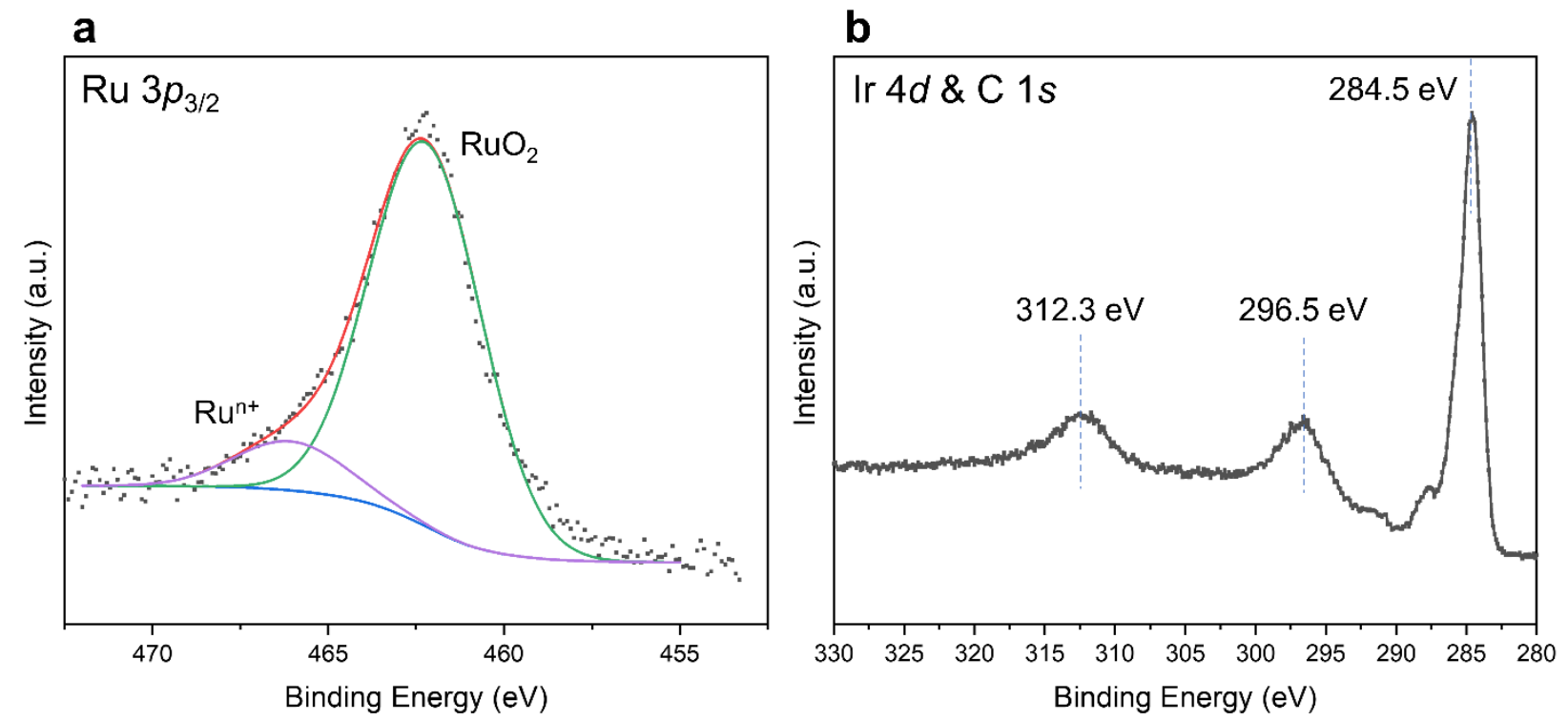

Figure S6. XPS profiles for (a) Ru 3p $3 / 2$ region of ZIF-67/Ru and (b) Ir $4 d \& \mathrm{C} 1 s$ region of ZIF-67/Ir.

Note: For ZIF-67/Ru sample, the peak at $462.2 \mathrm{eV}$ is assigned to $\mathrm{RuO}_{2}$ and the peak at 466.09 $\mathrm{eV}$ is assigned to higher oxidation states. ${ }^{13}$ For ZIF-67/Ir sample, the peak at $296.5 \mathrm{eV}$ is assigned to metallic Ir. ${ }^{14}$ These corroborate the findings in Figure 9. 


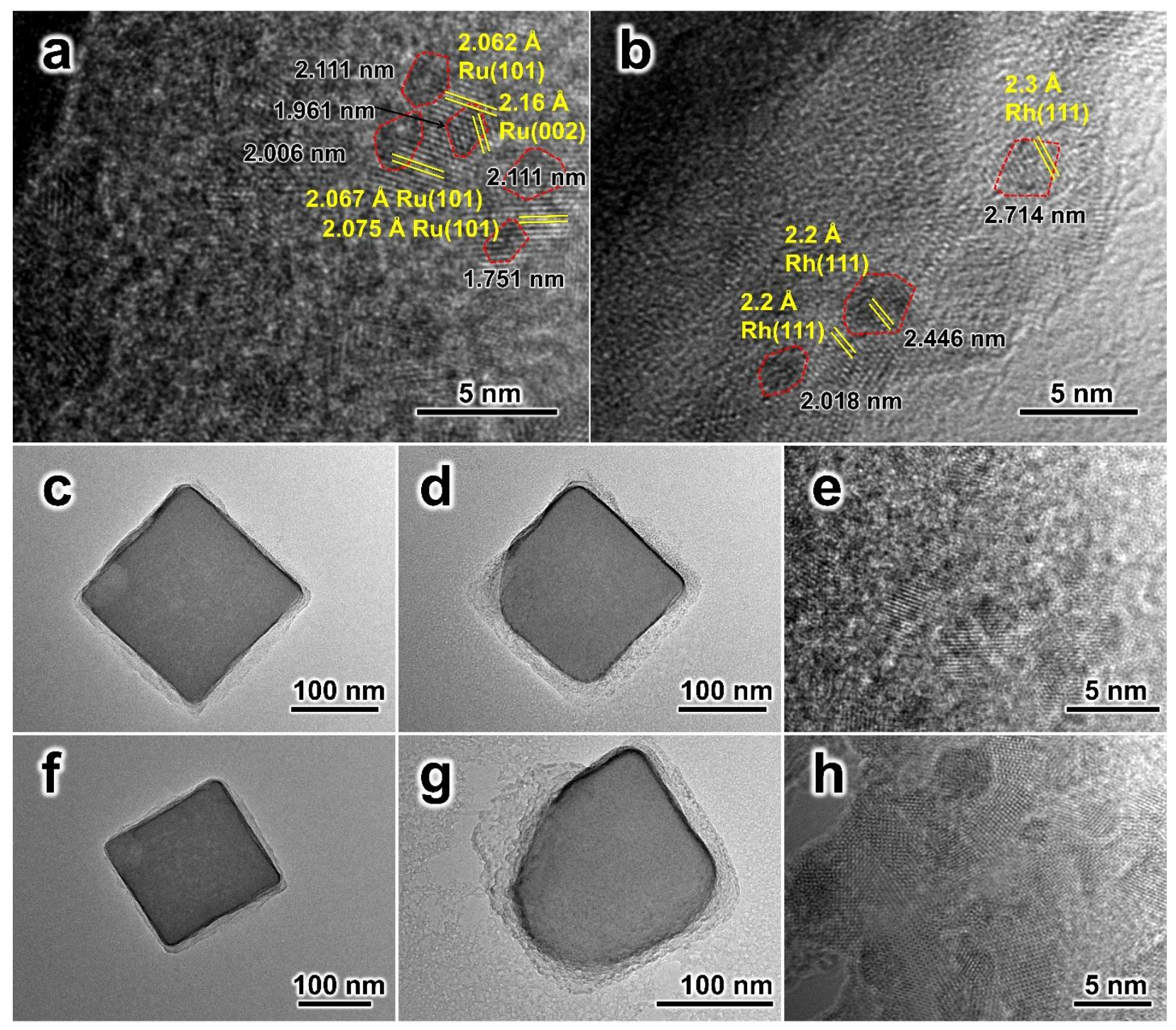

Figure S7. HRTEM images of ZIF-67/Ru and ZIF-67/Rh samples: (a) High magnification image of ZIF-67/Ru, and (b) High magnification image of ZIF-67/Rh. Yellow lines highlight the lattice fringe pattern. The lattice fringe sizes $(\AA)$ are measured and presented in yellow. Dashed red contours highlight the interested metal nanoparticles adjacent to the measured lattice fringe patterns. The dimensions $(\mathrm{nm})$ of the nanoparticles are measured and presented in black: (c, d) ZIF-67/Ru NC before and after observation at high magnification, respectively, (e) ZIF-67/Ru after prolonged observation at high magnification, (f, g) ZIF-67/Rh $\mathrm{NC}$ before and after observation at high magnification, respectively, and (h) ZIF-67/Rh after prolonged observation at high magnification.

Notes:

In the first row of HRTEM images (Figure S7a-b), lattice fringe patterns corresponding to metallic Ru and Rh are clearly observed. The dimensions of the metal NPs in vicinity of these 
patterns are measured and they agree with the particle size distribution previously measured at low magnifications. It is hence concluded that the metal NPs observed at low magnifications in the main text (Figure 5m-p) are in metallic state and the measured particle size distributions reflect the dimensions of metallic NPs, considering that: (1) XPS profiles (Figure 9) of Pt and Ir NPs suggests the majority of them are in metallic state, and (2) Metallic $\mathrm{Ru}$ and Rh NPs observed at high magnification possess the similar dimensions as those observed at low dimensions.

It is worth mentioning that the dimensions of Ru and Rh NPs in Figure S7a-b are relatively large due to the following reasons: (1) The lattice patterns are more appreciable around larger NPs. Hence those smaller NPs are ignored, but they are still recognizable in the HRTEM images, and (2) The particle dimensions are measured as the distance between two farthest points on the contour.

Figure S7c-h compare the ZIF-67/Ru and ZIF-67/Rh NCs before and after being observed at high magnification under TEM conditions. The observation mainly focuses on the edges as there is better contrast for the metal NPs. In Figure S7c, d, f, g, the destructive effect imposed by the electron beam of TEM on the ZIF-67 material can be clearly seen. Despite of the destruction of the ZIF-67 material, the Ru and Rh NPs can still retain as individual NPs and no perceptible agglomeration occurs as seen in Figure S7e, h. 

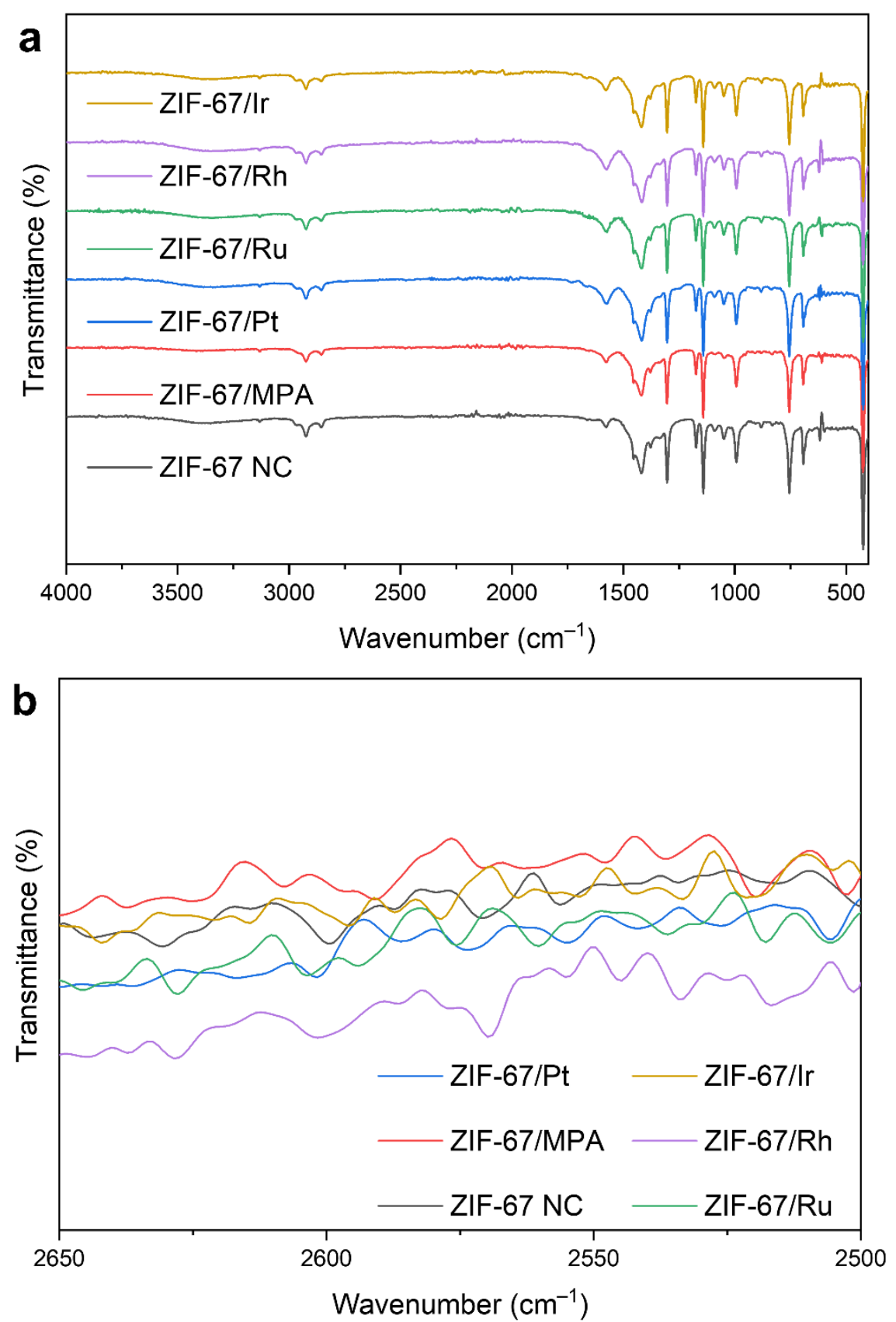

Figure S8. (a) FTIR spectra for ZIF-67 NCs, ZIF-67 treated with MPA (ZIF-67/MPA) and ZIF$67 / \mathrm{M}$ samples prepared via the post-synthesis attachment method, and (b) enlarged view of $2650-2550 \mathrm{~cm}^{-1}$ region.

Note: Hardly, any obvious changes could be observed before and after the post-synthesis attachment procedure to load the pre-synthesized metal NPs. It is thus inferred that minimal influence on the chemical bonding was imposed by the MPA molecules during this process. The characteristic thiol (S-H) stretching at $2600-2550 \mathrm{~cm}^{-1}$ are absent for all the MPA-containing samples, because the all the thiol groups are either neutralized with 2-MeIm or bind to metal NPs. 

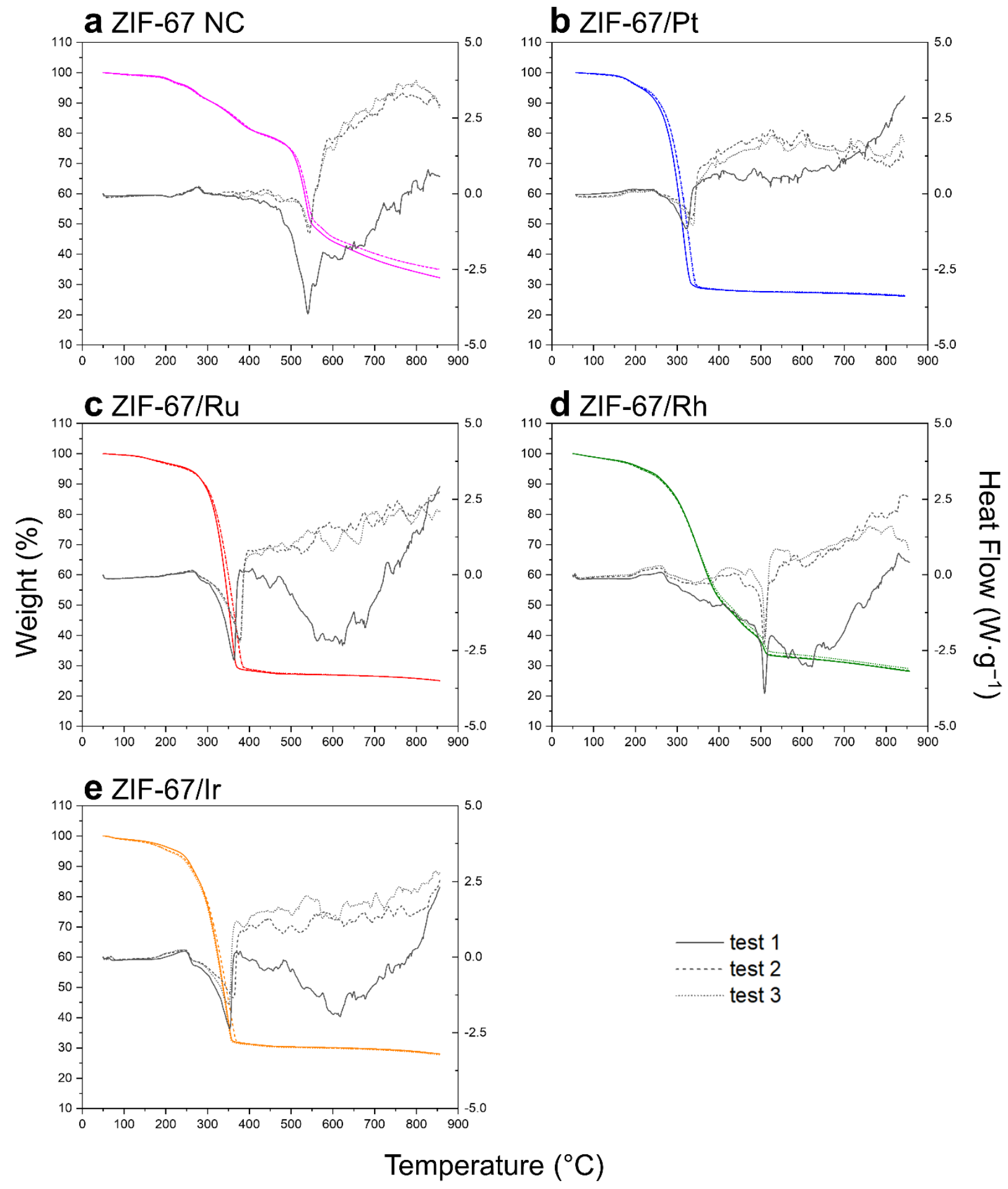

Figure S9. TGA-DSC profiles for $\mathrm{H}_{2}$-TGA experiments performed with (a) ZIF-67 NC, (b) ZIF67/Pt, (c) ZIF-67/Ru, (d) ZIF-67/Rh, and (e) ZIF-67/Ir samples, respectively.

Notes: 
This figure is supplementary to Figure 10a in the main text, displaying the differential scanning calorimetry (DSC) curves corresponding to each TGA experiment manifested in Figure 10a. The left $y$-axis represents the weight (\%) compared to the original weight of the sample and the right $y$-axis represents the heat flow $\left(\mathrm{W} \cdot \mathrm{g}^{-1}\right)$ at the specified temperature.

It is clearly demonstrated by the DSC curves that, an obvious endothermic peak corresponding to the major weight loss stage (also the most rapid weight loss period) can be found for each TGA experiment. This is indicative of the major hydrogenolysis event. Hence, the temperatures corresponding to 30 to $50 \mathrm{wt} \%$ weight loss were used to compare the hydrogen spillover ability, as mentioned in the main text.

It is also noteworthy that, as the TGA experiments were performed on different dates and with different reference crucibles, the heat flow curves may vary due to the different reference crucibles used. However, similar to those TGA curves showing high consistency among all three tests, the DSC curves indicate major endothermic peaks at rather close temperature ranges for all three tests. This further affirms the reliability of our experiments. Besides, the endothermic DSC peaks for ZIF-67/Rh occur at a higher temperature, indicating a weaker hydrogen spillover ability of Rh metal. This agrees well with our findings concluded in the main text. 

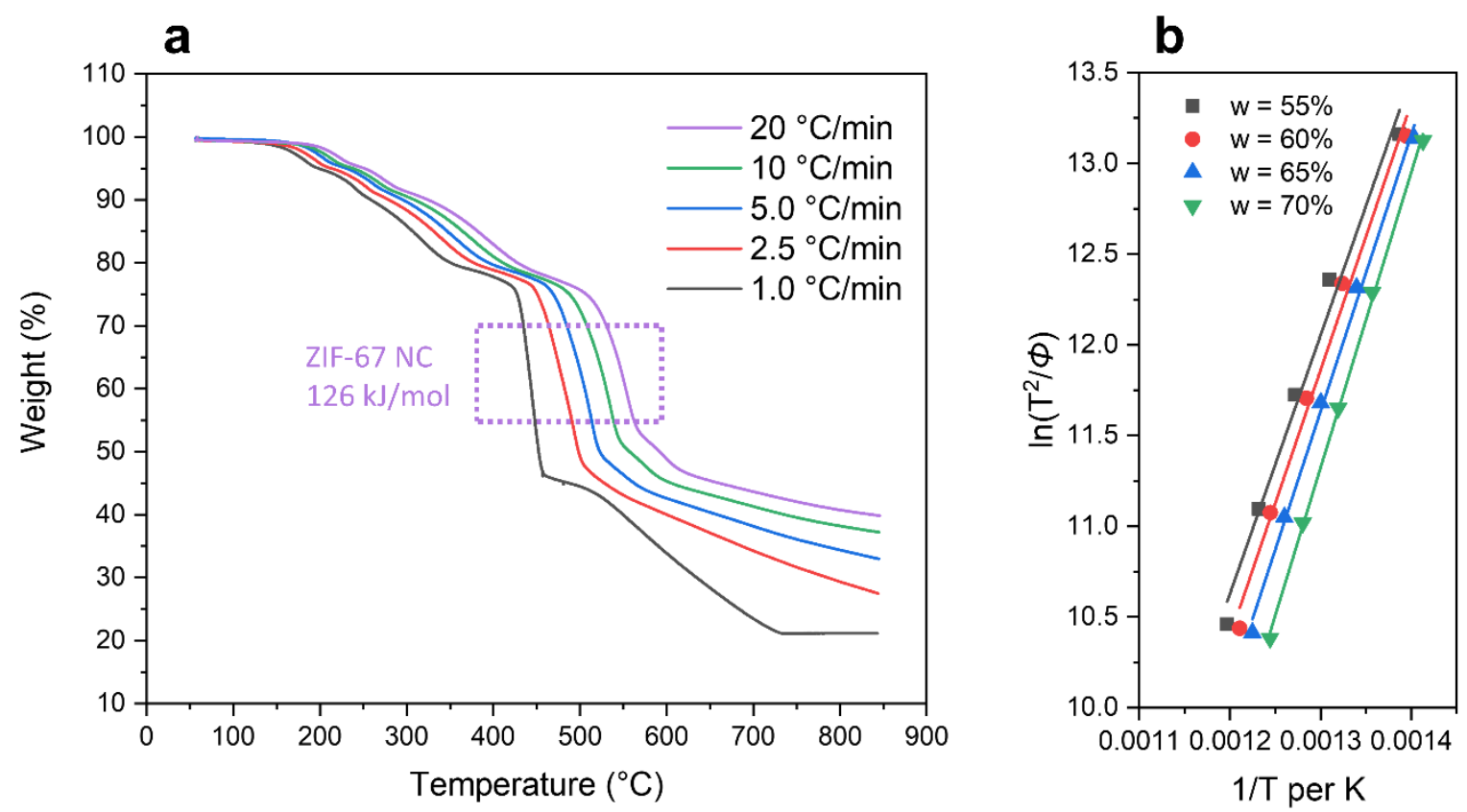

Figure S10. (a) TGA profiles for ZIF-67 NCs at varying heating rates $(1,2.5,5,10$ and $\left.20{ }^{\circ} \mathrm{C} \cdot \mathrm{min}^{-1}\right)$ in $\mathrm{H}_{2}$ flow $\left(50 \mathrm{~mL} \cdot \mathrm{min}^{-1}, 4.2 \mathrm{vol} \% \mathrm{H}_{2}\right.$ in $\left.\mathrm{N}_{2}\right) \cdot x$-axis represents temperature $\left({ }^{\circ} \mathrm{C}\right)$ and $y$-axis represents fractional weight (wt\%). (b) The corresponding $\ln \left(T^{2} / \phi\right) v s .1 / T$ plot for the indicated (dashed box) fractional weights.

Note: Pristine ZIF-67 NCs display an activation energy of $126 \mathrm{~kJ} / \mathrm{mol}$ for hydrogenolysis under the specified $\mathrm{H}_{2}$ atmosphere. This value is significantly higher than those deposited with Pt NPs ( 85 and $93 \mathrm{~kJ} / \mathrm{mol}$ ), advocating for the hydrogen spillover effect induced by Pt NPs. However, the activation energies for both the pristine ZIF-67 NCs and ZIF-67/Pt studied are higher than the reported values in our previous study. ${ }^{9}$ This could be attributed to several factors: (1) a higher ligand-to-metal ratio (64:1 vs. $42.5: 1$ ) was used in this study to construct more stable ZIF-67 material, which would be more resistant to hydrogenolysis at lower temperatures and decompose in narrower temperature intervals; (2) $\mathrm{R}^{-\mathrm{NBH}_{4}}$ used in the in situ reduction method may deteriorate the ZIF-67 material, making it more vulnerable at lower temperatures; and (3) sub-nanometer sized Pt NPs may be generated from the in situ reduction, yet being undetectable under TEM. These smaller Pt NPs may trigger the hydrogenolysis at lower temperatures as well as facilitate the overall process. It was observed that the hydrogenolysis of ZIF-67/Pt sample prepared via in situ reduction method is more active at lower temperatures than those prepared via MPA-bridging method, indicated by weight loss at early stages (weight loss $<20 \%$ ). In addition, ZIF-67/Pt prepared via MPAbridging method display rapid hydrogenolysis in narrower temperature intervals, suggesting a narrow Pt NP particle size distribution. 


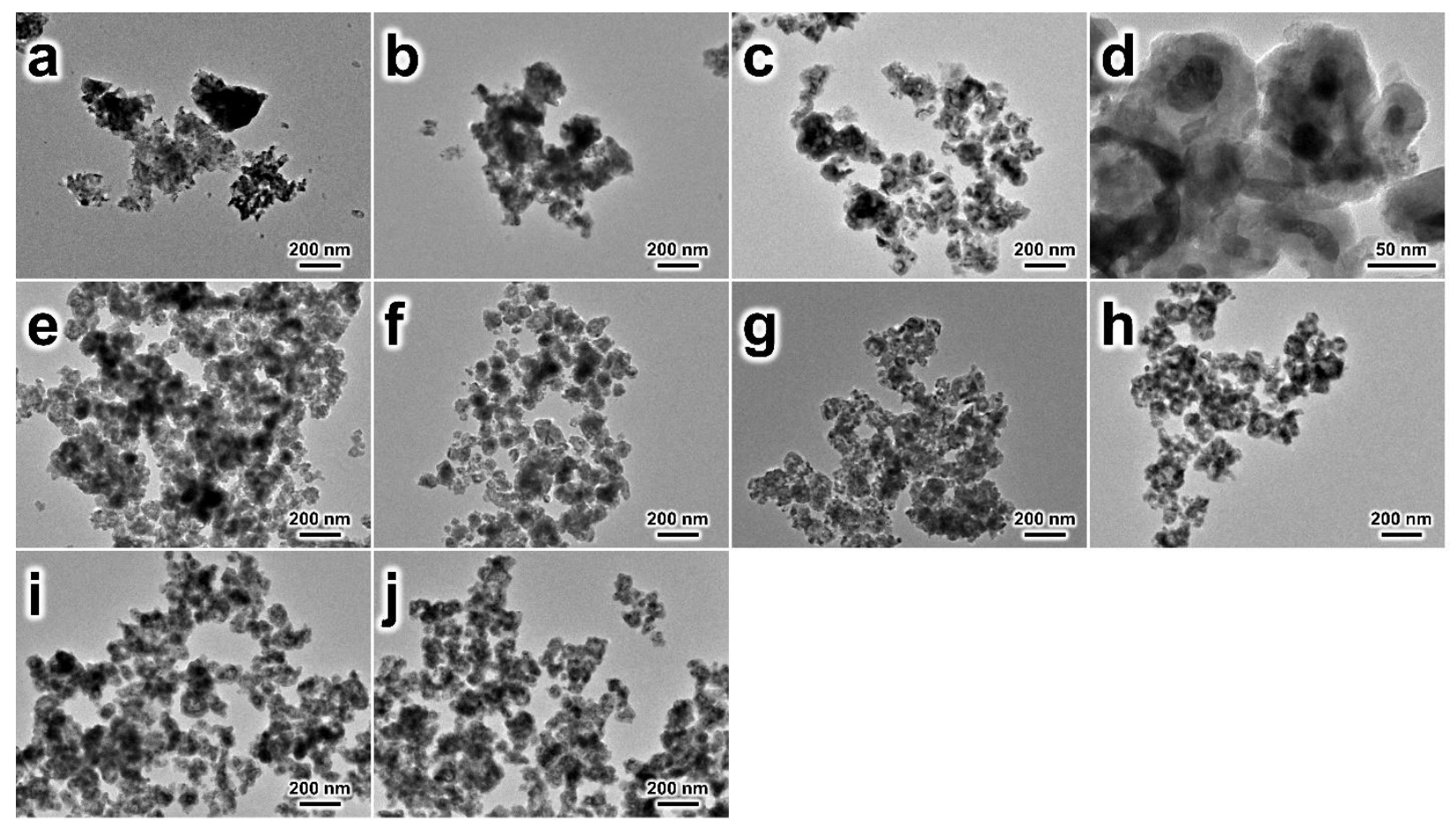

Figure S11. TEM images of the spent ZIF-67/M samples after the TGA experiments: (a, b) spent ZIF-67/Pt prepared via the in situ reduction method, (c, d) spent ZIF-67/Pt prepared via MPA-bridging method, (e, f) spent ZIF-67/Ru prepared via MPA-bridging method, (g, h) spent ZIF-67/Rh prepared via MPA-bridging method, and (i, j) spent ZIF-67/Ir prepared via MPA-bridging method. 


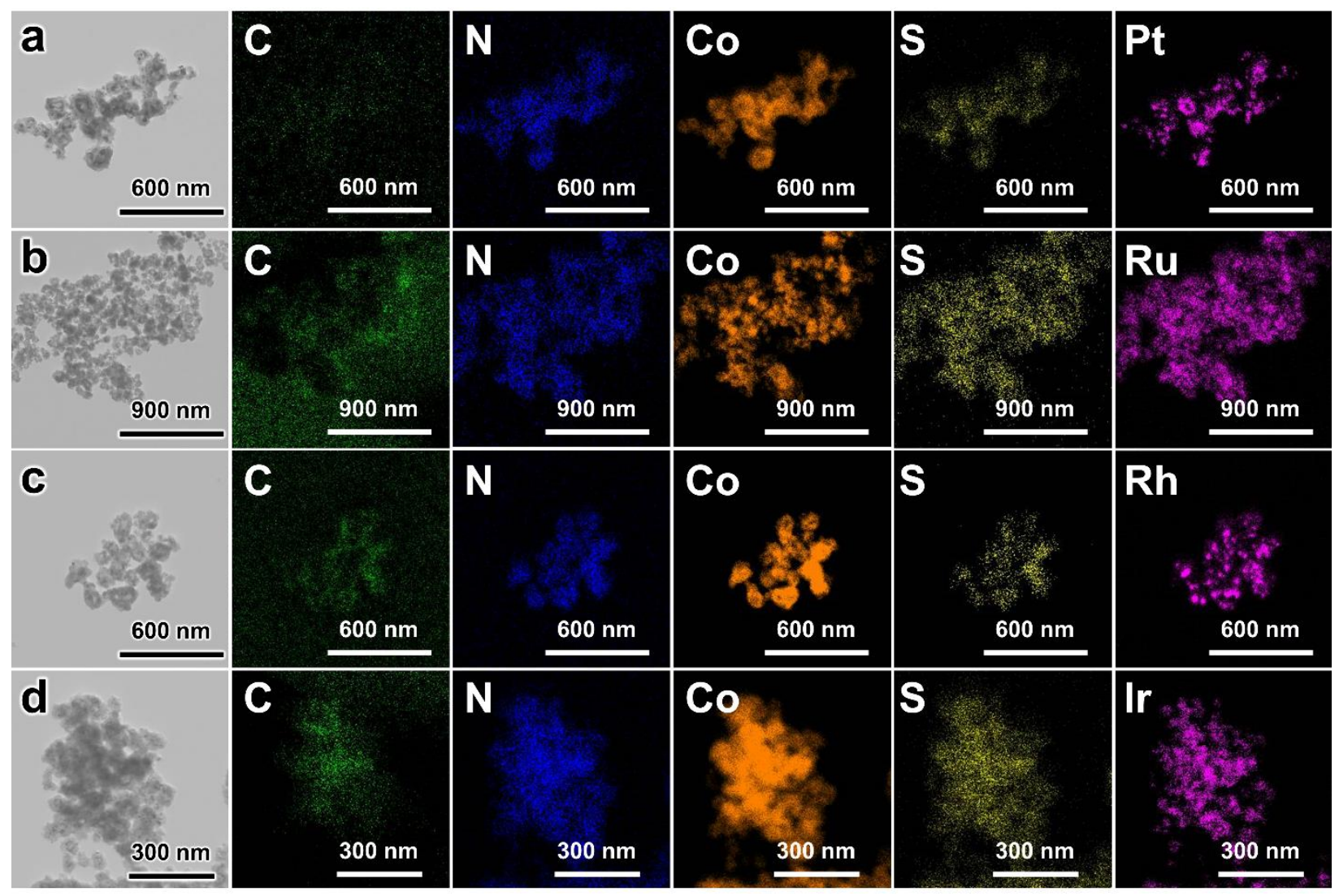

Figure S12. EDX elemental mappings for four ZIF-67/M samples after the TGA experiments: (a) spent ZIF-67/Pt, (b) spent ZIF-67/Ru, (c) spent ZIF-67/Rh, and (d) spent ZIF-67/Ir. Color codes: green represents carbon, blue represents nitrogen, orange represents cobalt, yellow represents sulfur, and magenta represents the deposited metal (Pt, Ru, Rh, and Ir).

\section{References}

1. Lebedeva, O. E.; Chiou, W.-A.; Sachtler, W. M. H. Metal Migration from Zeolites onto Iron Oxide: An Alternative to Hydrogen Spillover. J. Catal. 1999, 188, 365-374.

2. Duan, H.; Xu, D.; Li, W.; Xu, H. Study of the Redox Properties of Noble Metal/Co3O 4 by Electrical Conductivity Measurements. Catal. Lett. 2008, 124, 318-323.

3. Xu, D.; Li, W.; Duan, H.; Ge, Q.; Xu, H. Reaction performance and characterization of $\mathrm{Co} / \mathrm{Al}_{2} \mathrm{O}_{3}$ Fischer-Tropsch catalysts promoted with Pt, Pd and Ru. Catal. Lett. 2005, 102, 229235.

4. Nakano, K.; Kusunoki, K. Role of Hydrogen Spillover in a Hydrogenation Reaction on Monometallic (Ru, Rh, Pd, or Pt) and Bimetallic (Ru-Pd) Catalysts. Chem. Eng. Commun. 2011, 34, 99-109.

5. Villarroel, M.; Méndez, A.; Águila, G.; Escalona, N.; Baeza, P.; Gil-Llambías, F. Synergism in alumina-supported noble metals and molybdenum stacked-bed catalysts via spillover hydrogen in gas-oil hydrodesulphurization. Catal. Today 2010, 156, 65-68. 
6. Boccuzzi, F.; Chiorino, A.; Ghiotti, G.; Guglielminotti, E. Metal/n-zinc oxide interaction: effect of the surrounding atmosphere on IR transparency. Langmuir 1989, 5, 66-70.

7. Mitchell, P. C. H.; Ramirez-Cuesta, A. J.; Parker, S. F.; Tomkinson, J.; Thompsett, D. Hydrogen Spillover on Carbon-Supported Metal Catalysts Studied by Inelastic Neutron Scattering. Surface Vibrational States and Hydrogen Riding Modes. J. Phys. Chem. B 2003, 107, 68386845.

8. Chen, X.; Huo, X.; Liu, J.; Wang, Y.; Werth, C. J.; Strathmann, T. J. Exploring beyond palladium: Catalytic reduction of aqueous oxyanion pollutants with alternative platinum group metals and new mechanistic implications. Chem. Eng. J. 2017, 313, 745-752.

9. Zhan, G.; Zeng, H. C. Hydrogen spillover through Matryoshka-type (ZIFs@)n-1ZIFs nanocubes. Nat. Commun. 2018, 9, 3778.

10. Li, Z.; Zeng, H. C. Surface and Bulk Integrations of Single-Layered Au or Ag Nanoparticles onto Designated Crystal Planes $\{110\}$ or $\{100\}$ of ZIF-8. Chem. Mater. 2013, 25, 1761-1768.

11. Tan, J. C.; Bennett, T. D.; Cheetham, A. K. Chemical structure, network topology, and porosity effects on the mechanical properties of Zeolitic Imidazolate Frameworks. Proc. Natl. Acad. Sci. U. S. A. 2010, 107, 9938-43.

12. Zhou, K.; Mousavi, B.; Luo, Z.; Phatanasri, S.; Chaemchuen, S.; Verpoort, F. Characterization and properties of Zn/Co zeolitic imidazolate frameworks vs. ZIF-8 and ZIF67. J. Mater. Chem. A 2017, 5, 952-957.

13. Morgan, D. J. Resolving ruthenium: XPS studies of common ruthenium materials. Surf. Interface Anal. 2015, 47, 1072-1079.

14. Xing, Y.; Ku, J.; Fu, W.; Wang, L.; Chen, H. Inductive effect between atomically dispersed iridium and transition-metal hydroxide nanosheets enables highly efficient oxygen evolution reaction. Chem. Eng. J. 2020, 395. 